\title{
The Effect of Queuing Technology on Customer Experience in Physical Retail Environments
}

\author{
Gabriele Obermeier ${ }^{(凶)}$, Robert Zimmermann, and Andreas Auinger \\ University of Applied Sciences Upper Austria, Steyr, Austria \\ \{gabriele.obermeier, robert.zimmermann, \\ andreas.auinger $\}$ afh-steyr.at
}

\begin{abstract}
Queuing systems manage the order of customers waiting for their service encounter fairly and equitably and influence the perception of their experience in a physical retail store. In this field study, we investigate a self-service and a human-operated queuing system, both offering additional features, designed to offer a higher level of personalization and convenience for the customer's waiting time. Our study shows that advanced queuing technologies in stores, with generally low customer frequency and short waiting times, show no statistically significant effect on a customer's perception of the overall customer experience, satisfaction or intention to repurchase. However, customers were satisfied with the technologies and evaluated their queuing experience as effortless, easy and quick, which shows general support for those technologies. Beyond the statistical analysis, our mixed-method approach contributes to a broad understanding of advanced queuing technology for practitioners, retailers and developers of such systems.
\end{abstract}

Keywords: Customer experience $\cdot$ Queuing $\cdot$ Self-service technology $\cdot$ Field study $\cdot$ Digital retail

\section{Introduction}

Waiting for service is one of the most unpleasant but unavoidable events in everyday life [1]. When we encounter a queue at medical facilities, hairdressers, banks or retail stores, our perception of the service delivery is directly affected [1]. Waiting was mentioned among the main reasons that encourage customers to buy online instead of visiting a physical store [2]. In the 1980s, scientists started to recognize the importance of queue management [3] and the impact of waiting time on customer experience [4]. In 1985, Maister [5] and Haynes [6] found that the feeling of equitability has a positive effect on the customer's perception of waiting time. Sasser et al. [7] observed that customers feel very angry if somebody successfully sneaks into the line ahead. In order to treat customers equitably and fairly, we often encounter queuing systems in stores, especially where products or services require customer-specific and intensive consultation. Queuing systems such as First-In, First-Out (FIFO) enable fair processing of lines, described as "social justice" by Larson [3]. One well-known example of a FIFO system is a ticket queue, in which customers receive a consecutive number by which customers are 
called out or which is displayed on a centrally placed monitor [8]. Those systems apply to so-called "invisible" queues, in which people are not standing in line one behind another [8]. A more recent study has shown that customers prefer invisible ticket queues above physical queues [9]. The development of information systems (IS) entails that firms increasingly provide technologies, such as self-service technology (SST), which have been introduced widely in retail environments [10]. Almost 30 years ago, the topic of SST in retail gained a lot of attention, when researchers of service literature began to examine relevant factors that are of great importance for customer participation with SSTs at servicescapes $[11,12]$. SSTs enable customers to take over control of the situation or transactions in waiting and queuing situations [11]. Convenience and the quick and accurate ability to perform the task, are necessary attributes $[13,14]$ in order to encourage customers to use SSTs. From the retailer's perspective, SSTs have mainly been introduced to save labour costs as machines are able to take over tasks from human beings [11].

We conducted face-to-face interviews with a qualitative and quantitative questionnaire after customers visited a telecommunications store in an Austrian shopping mall. Our study investigates the human-computer interaction between customers and a queuing technology based on the concept of ticketing and offered as both a self-service and human-operated system. In order to make the waiting time more pleasant for customers, the retailer's intentions by providing an advanced queuing system were, first of all, to offer customers the possibility to move freely around the closer area of the store or to use the time productively carrying out errands. Second, by being called upon by name, the telecommunication provider expects to provide a more personal entry into the service consultation between employee and customer. Finally, the goal was to improve the whole experience and to ensure the customer's intention to repurchase. Therefore, our work contributes to the understanding of the influence of in-store retail technology on customer experience, demonstrated by the usage of a queuing technology in a telecommunications store. Consequently, we pose the following research questions for this work: How does a queuing technology affect the customers' perception of the experience in a service-oriented retail store? Are there differences in interacting with humanor self-service-based queuing technologies?

The paper is organized in the following way. Section 2 provides the theoretical background on customer experience and SSTs in retail. Section 3 presents the queuing technology and its functionalities. Section 4 outlines the research methodology concerning participants and the questionnaire used in this work. The results are presented in Sect. 5 and structured based on the four different approaches of our study: First, we observed customers of a telecommunication store to evaluate their approach and avoidance behaviour when using SST. Second, we focused on measuring the cognitive, affective and physical first-order constructs in line with Bustamante et al.'s [15]. In-Store Customer Experience (ISCX) scale. Third, we investigated the customer's willingness to use additional functions of the SST, such as taking a picture to enable employees a faster recognition of the customer. Fourth, we outline the qualitative feedback of customers' overall satisfaction. Section 6 shows the findings of this study and gives recommendations for retailers. Further, the limitations of our study are discussed in this section. Concluding, Sect. 7, provides a summary of our findings. 


\section{Theoretical Background and Related Work}

Our study is based on two topics: First, we will define the construct of customer experience and discuss the term in association with the importance of queuing. Second, we will present related work in IS research on self-service technologies in retail environments.

\subsection{In-store Customer Experience}

Queuing theory is a formal concept applied in service-oriented industries and studied in the field of operations management improving the flow of queues, such as in hospital pharmacy [16]. Maister [5], who analysed queuing from the psychological and behavioural perspective, claims that the customer's entire perception of service quality is significantly influenced by the experience in the queue. Service and customer experience are often used interchangeably in service research [17]. As stated by Meyer et al. [18], customer experience can be defined as "[...] the internal and subjective response customers have to any direct or indirect contact with a company. Direct contact generally occurs in the course of purchase, use, and service and is usually initiated by the customer" (p. 1). To Lemon et al. [19] customer experience is "[...] holistic in nature and involves the customer's cognitive, affective, emotional, social and physical responses to the retailer" (p. 70). Bustamante et al. [15] designed the ISCX-scale, a third-order formative model, to measure cognitive, affective, social and physical experiences in physical retail environments. ISCX stands for In-Store Customer Experience and is based on the Strategic Experiential Modules (SEMs) as proposed by Schmitt [20]. SEM proposes to strategically create customer experience with elements that influence the human's state of mind and behaviour, such as affective and cognitive experiences [20], which can be explained as follows: Affective customer experiences such as being in a good mood or feeling contented or surprised [15] are human emotions that influence customer experience and behavioural outcomes [21]. Dahm et al. [22] reported that the affective state of mind in queues at supermarket checkouts shows a strong negative effect as the number of people increases in the line behind the focal customer. The emotional elements related to the shopping experience are excluded if shopping trips are assessed mainly for utilitarian reasons [23] or if customers are exposed to an unknown situation at the service encounter [11]. In this case, the psychological concept of cognitive experience is more active. The cognitive state of mind is defined as a person's conscious thinking, allowing people to create opinions, receive, and process information, and evaluate their environment [24]. Cognitive states of mind occur when the shopping environment awakens curiosity, inspiration, or interest [15]. The physical element of customer experience refers to the retailer's environment, the products in the store, as well as its personnel, and practices [15]. According to Schmitt [20], the physical experience relates to the active verb "act", as well as to motivational and inspirational feelings. The use of instore technology has an impact on consumers' perception of the atmosphere in physical retail stores [25]. Retailers can use this knowledge to introduce triggers in the retail environment, such as SSTs, through which the customer's thinking engages [15]. De Keyser et al. [26] emphasize that in-store technology plays an important role in customer experience. Consequently, behavioural outcomes, such as customer satisfaction $[19,27-30]$ and intention to repurchase (IR) [29, 31, 32] (as part of customer loyalty) are 
both factors used by researchers and practitioners to evaluate how customers perceived their shopping experience.

\subsection{Self-service Technologies in Retail Environments}

Few field studies about SSTs in physical retail environments have been conducted in the past decade [33]. Numerous researchers use the well-known TAM as the theoretical basis on technology acceptance of decision support technologies [13, 34]. Moreover, many studies focus on decision support technologies, such as Djelassi et al.'s [10] work on the experience with self-checkout and self-scanning devices and perceived waiting time. The authors proved that the satisfaction with the technology increases the more interactively the SST has been designed (e.g., self-scanning). Even though the authors showed a link to overall satisfaction with the store, this connection is more difficult to establish as customers might attribute the experience with SSTs to themselves rather than to the store. Dabholkar [11] was one of the first who studied the influence of SST usage on perceived service quality and the effect of cognitive and affective perception of waiting. In any waiting situation, control has been found to be a strong determinant of service quality, as well as enjoyment for long waiting times. Roy et al. [32] performed an online questionnaire on multiple smart retail technologies, such as smart checkouts, personal shopping assistance, and point of sale smart displays. All of these technologies promoted a positive influence of the SST on the customer's satisfaction. Various studies on queuing systems and waiting emotions can also be found in the literature on hospitality [35], transportation [36], and operations management [37].

The objective of our study is to investigate whether queuing technology affects the perceived customer experience of the queuing process in retail environments. For this purpose, we used an SST and a human-operated queuing system, both of which were evaluated by customers. The goal is to draw conclusions that support practitioners in developing in-store technologies as well as to make retailers aware of important factors when implementing in-store technology.

\section{The Functionality of the Queuing Technology}

This study discusses queuing technologies, which are implemented at stores of several telecommunication providers. Those stores are typically consultancy-intensive as the majority of customers demand an individual consultation by a service employee. Depending on the frequency in the store, customers need to wait for a personal service encounter. The advanced queuing technology presented in this study aims to create an enhanced customer experience and to offer a pleasant perception of the unavoidable waiting time. The system has been developed by an Austrian retail-software and consulting company specialised on in-store technologies. The hardware supplier, an international IT-systems company, provides devices with touch-screen monitors for all kinds of selfservice encounters. The web application is developed in responsive design, enabling an automatic adjustment of the content on any device and screen size [38]. Therefore, the application can be used as SST on a touch-screen monitor, as well as from a 'Human Greeter' (HG), in order to arrange the next possible service encounter with another 
employee. The HG refers to an employee who welcomes customers at the entrance of the store and queues them by using a portable tablet computer with the same software. If the HG is not present or busy queuing others, customers are offered the possibility of using the SST at the entrance of the telecommunications store. See Fig. 1.

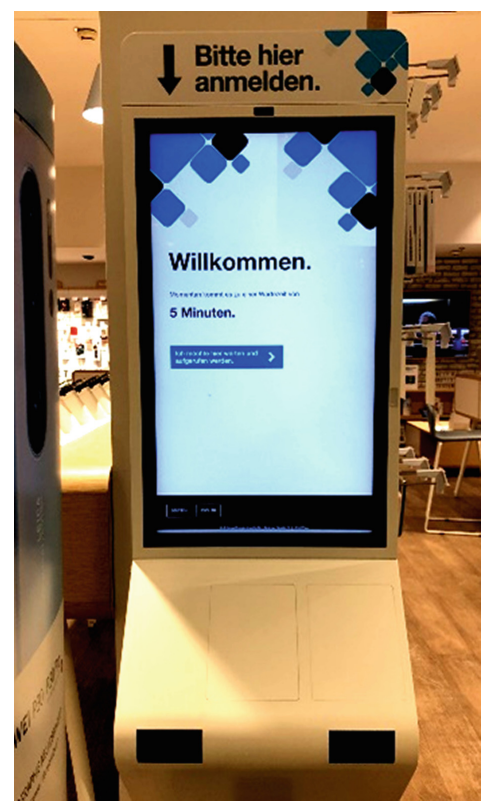

Fig. 1. Self-service technology in a telecommunication retail store. Note: Photo has been adjusted for reasons of secrecy

During the process of queuing, customers decide on how they would like to be notified about the upcoming service encounter. Customers can either be called using their name as given to the HG/SST or informed by a text message five minutes prior to the appointment. Both options require the input from the customer at a keyboard on the touch screen or waiting for the HG to enter the information. It is also possible for users of the SST to skip those options by clicking on the "Continue" button several times. In this case, the system creates a consecutive ticket number by default. Both queuing possibilities (SST/HG) provide an estimated waiting time, which is automatically calculated by the number of employees logged in to the system and the number of customers in consultancy or waiting ahead. In case of low frequency in the store, customers tend to directly approach the counter of a free employee instead of queuing. Figure 2 gives an overview of the possibilities of approaching a service encounter at the retail store.

The main purpose of the queuing technology, as described by the developer, is to provide a convenient and fair FIFO-queuing-process in which customers are not forced to stay in the store during the waiting time and leave the store perceiving a great customer experience. 


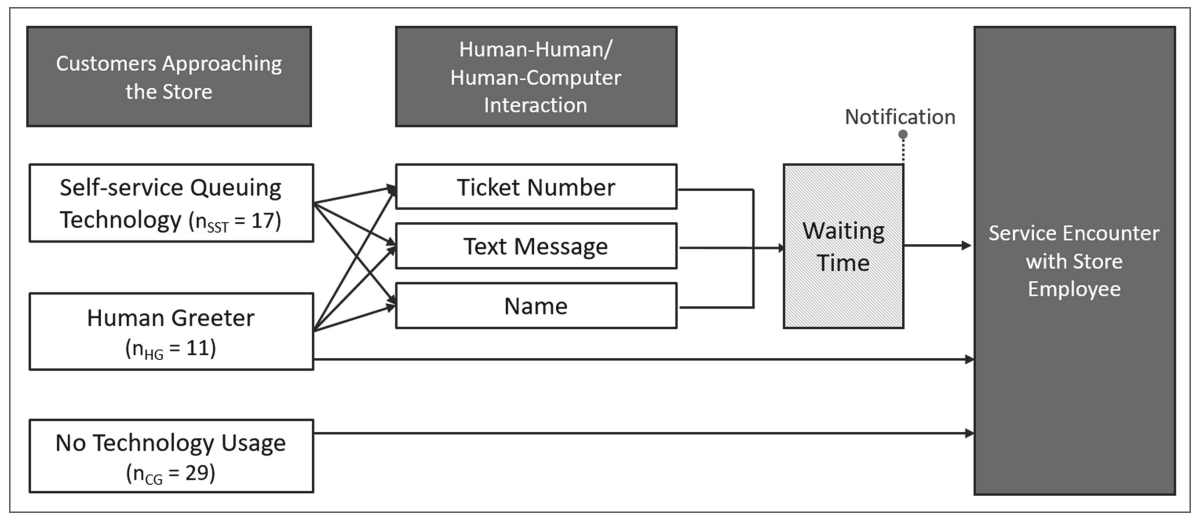

Fig. 2. Queuing process at the telecommunication store

\section{Research Design and Methodology}

In order to investigate the customer's perception of the queuing technology, a mixedmethods field study has been carried out in one of the telecommunication provider's stores located in a shopping mall in Vienna, Austria. We did not interfere in the daily business for our study. Firstly, we observed how customers approached the retail store and their behaviour with the SST or the service employee as HG. Secondly, we investigated the impact of queuing technology on customer experience and consequently on satisfaction and intention to repurchase. In this case, data has been collected by a quantitative approach. Thirdly, we got deeper insights from a quantitative evaluation of the customer's technology usage. In the last step, customers expressed the overall satisfaction in their own words. The following subsections will provide the segmentation of participants, as well as the data collection procedure.

\subsection{Participants}

In total, 60 interviews were completed on four days in June and July 2019 at the entrance of a telecommunications store in a well-established shopping mall in Vienna. While considering the gender balance, customers were chosen at random to participate in a structured face-to-face interview using quantitative and qualitative questions after their store visit and were not aware of the questionnaire in advance. Each day, there were between 60 and 70 people visiting the store. Because of the relatively low customer traffic on the days of observation, the majority of customers were able to approach an employee directly or did not have to wait for more than one minute before their appointment came up. Overall, the survey was conducted with approximately $20 \%$ of the total amount of people having a service consultation with one of the store's employees on each of the four survey days. To reduce a negative emotional bias in the statistical analysis, we excluded three people whose problems could not be solved by the company and subsequently rated their overall experience as "(very) bad". Consequently, the resulting sample included 57 persons between the age of 17 and 75 (mean age $=37.89, \mathrm{SD}=13.968)$, of which 
29 were men (50.9\%) and 28 were women $(49.1 \%)$. We split the participants into two experimental groups who either used the SST to get a queuing ticket $\left(\mathrm{n}_{\mathrm{SST}}=17\right)$ or were queued by the $\mathrm{HG}\left(\mathrm{n}_{\mathrm{HG}}=11\right)$. The control group consists of 29 participants $\left(\mathrm{n}_{\mathrm{CG}}\right.$ =29) who did not have contact with either the SST or the HG. These customers directly approached free service employees or were offered help without queuing. In total, $85 \%$ of participants had been regular customers of the telecommunications provider before they entered the store on the respective day of the investigation. More than three quarters had already encountered self-service queuing technology before of which $20 \%$ knew the system from this retail store and $27 \%$ from another location.

\subsection{Questionnaire}

To measure customer experience in a retail store we adapted a questionnaire design proposed by Bustamante et al. [15]. The scale measures participant's cognitive (3 items), affective (3 items) and physical experience (3 items). Contrary to Bustamante et al. [15], we did not include questions about the social construct to focus on the evaluation of the store and the use of the technology, independent of the employees' consultancy and service abilities. All items were measured with a Likert scale ranging from 1 ('highly disagree') to 5 ('highly agree'). The questionnaire was conducted with survey software Questback [39] running on a tablet device. According to the automatic logging, the completion of the questionnaire took an average of $8.5 \mathrm{~min}$. Additionally, our questionnaire addressed participants' overall satisfaction with the store (1 item) and intention to repurchase (1 item) both derived from Turner and Schockley [29]. We also included sample selection questions (2 items), asked for participants' previous SST experience (1 item [10]), trust in the SST (4 items [40]), satisfaction with the queuing system (1 item [29]) and participant's demographics (3 items). For the open question on overall experience [29], customers' answers were written down by the researcher in an open text field on the tablet device. Furthermore, we collected the customers' self-evaluation on technology readiness (2 items [41]) and need for interaction (2 items [42]).

\section{Results}

The evaluation of the results is divided into four categories: First, we present the observations from the field. Second, we conducted a statistical analysis in which Bustamante et al.'s [15] ISCX scale is used. Third, we present the findings from the customer's evaluation of the interaction with the SST. Finally, we evaluate customers' qualitative feedback on the overall experience.

\subsection{Situational Observation of Customers Entering the Store}

An initial concern was whether shoppers entering the store would notice the SST and start the queueing procedure. We observed that some shoppers who stopped and looked at the monitor did not instantly interact with it. In this case, the customers were either able to directly approach a service employee because of low frequency in the store or were directed to the SST by an employee. The purpose of the SST was not obviously clear to 
users, who had not been in contact with the system before. Those customers were able to use it after reading the text on the screen, being informed by an employee or watching other people using the SST. Still, they were looking for a monitor where they could check their waiting number and how many people were ahead in the queue. Experienced customers, who obviously knew the system already, immediately approached the SST. The majority of customers were busy checking whether the company was calling up customers in the right order and that no other customers were jumping the queue. Two customers who had been welcomed by the HG directly asked if he could take care of their problem directly instead of providing a queuing number.

\subsection{Statistical Analysis of Customer Experience}

In the following subsections, we present the findings from our statistical analyses on customer experience, satisfaction and intention to repurchase. Respective group differences and effect sizes are provided as well.

Descriptive Statistics. After the store visit, customers were asked questions about their cognitive, affective and physical experience in the store. Skewness and kurtosis values suggest all items deviate from a normal distribution. This is further confirmed by the very significant $\mathrm{p}$ values of the Kolmogorov-Smirnov test and Shapiro-Wilk test, which in total suggest the validity of non-parametric testing. Due to their non-parametric nature, a Kruskal-Wallis test was used to check whether the customer experience of people using SST, HG and control group differs significantly from each other. Furthermore, a MannWhitney U test with Bonferroni corrected significance level was conducted to pinpoint the differences between SST, HG and control group. Finally, we tested the effect size of the discovered differences by using Cohen's d. The software SPSS (v. 26) [43] was used to analyse the data of our questionnaire. The results of the descriptive statistics on customer experience, satisfaction, and intention to repurchase are presented in Table 1.

Group Differences and Effect Sizes. We conducted a Kruskal-Wallis test for nonparametric statistics and small samples to analyse differences in customer experience between participants who did not queue by using technology (control group) and the ones who either used the SST or were queued by the HG. We observed no significant differences in customer experience perception between HG, SST and control group except for the cognitive item "Interest". Consequently, the item was analysed with a MannWhitney U test for each group combination to discover which groups significantly differ from each other. The results are outlined in Table 2.

As Table 3 shows, the Mann-Whitney $U$ test $(U=143.5)$ shows a significant difference $(p=0.0155)$, even at the Bonferroni adjusted significance level $(p=0.016)$, of the cognitive item "Interest" between the control group (Median =4) and SST (Median = 3 ). The effect size according to Cohen [44] is $d=0.737$ which represents a medium to large effect.

\subsection{Quantitative Analysis of Interaction with SST}

We evaluated customers' perceived convenience using the SST by the questionnaire items effort, easiness, and quickness adapted from Colwell et al. [10]. The analysis shows that 
Table 1. Descriptive statistics

\begin{tabular}{|c|c|c|c|c|c|c|}
\hline Item & M & SD & Skew. & Kurt. & $\mathrm{K}-\mathrm{S} / \mathrm{p}^{\mathrm{a}}$ & $\mathrm{S}-\mathrm{W} / \mathrm{p}$ \\
\hline \multicolumn{7}{|l|}{ Cognitive } \\
\hline \multicolumn{7}{|c|}{ The environment of this retail store, the display of its products, services, etc.: } \\
\hline $\begin{array}{l}\text { C1. Awaken my } \\
\text { curiosity }\end{array}$ & 3 & 1.088 & -0.325 & -0.271 & $0.193 /<0.001$ & $0.906 /<0.001$ \\
\hline C2. Inspire me & 3 & 1.093 & 0.118 & -0.258 & $0.221 /<0.001$ & $0.903 /<0.001$ \\
\hline C3. Interest me & 3 & 1.217 & -0.323 & -0.712 & $0.185 /<0.001$ & $0.905 /<0.001$ \\
\hline
\end{tabular}

The environment of this retail store, the display of its products, services, etc., make me feel:

\begin{tabular}{l|l|l|l|l|l|l}
\hline $\begin{array}{l}\text { A1. In a good } \\
\text { mood }\end{array}$ & 4 & 0.934 & -0.551 & 0.205 & $0.231 /<0.001$ & $0.872 /<0.001$ \\
\hline A2. Contented & 4 & 0.844 & -0.437 & -0.599 & $0.22 /<0.001$ & $0.843 /<0.001$ \\
\hline A3. Surprised & 3 & 1.187 & 0.038 & -0.817 & $0.156 / 0.001$ & $0.918 / 0.001$ \\
\hline
\end{tabular}

Physical

The environment of this retail store, the display of its products, services, etc., make me feel:

\begin{tabular}{l|l|l|l|l|l|l}
\hline P1. Comfort & 4 & 0.964 & -0.387 & -0.738 & $0.243 /<0.001$ & $0.866 /<0.001$ \\
\hline P2. Energy & 4 & 0.772 & -0.780 & 2.185 & $0.291 /<0.001$ & $0.811 /<0.001$ \\
\hline P3. Well-being & 4 & 0.789 & -0.484 & -0.551 & $0.23 /<0.001$ & $0.824 /<0.001$ \\
\hline $\begin{array}{l}\text { Overall } \\
\text { satisfaction }\end{array}$ & 5 & 0.331 & -2.361 & 3.703 & $0.522 /<0.001$ & $0.385 /<0.001$ \\
\hline $\begin{array}{l}\text { Intention to } \\
\text { repurchase }\end{array}$ & 5 & 1.101 & -1.747 & 1.704 & $0.437 /<0.001$ & $0.582 /<0.001$ \\
\hline
\end{tabular}

${ }^{a}$ Lilliefors Significance Correction

Note: Median (M), Standard Deviation (SD), Skewness (Skew.), Kurtosis (Kurt.), KolmogorovSmirnov test (K-S), Shapiro-Wilk (S-W) test and their significance (p)

customers $(\mathrm{n}=28)$, independently of the self-service or human-operated technology, rated the three convenience items with the maximum value. Only one person chose the second-best possible answer for the quickness with the HG.

Furthermore, the survey contained questions about using the additional functions of the SST as presented in the aforementioned Sect. 3. In this section, customers evaluated their willingness to expose their real name and phone number (only available for SST users) for an intentionally more personalized customer experience. In total, nine of 17 SST users and two of eleven HG users were willing to reveal their name. Regardless of SST or HG, customers were, except for one person (Likert-rating: 4), very satisfied with the queuing process (Likert-rating: 5).

Overall, it can be stated that trust towards the company itself (median $=4.5$ ) was rated slightly higher than trust with regard to the deletion of the data after the store visit (median $=4.0$ ). It needs to be stated that there is no clear evidence for the items "trust" 
Table 2. Group differences SST, HG and control group

\begin{tabular}{|c|c|c|c|}
\hline Item & Kruskal-Wallis H & df & Asymp. Sig. \\
\hline \multicolumn{4}{|l|}{ Cognitive } \\
\hline $\begin{array}{l}\mathrm{C} 1 . \text { Awaken my } \\
\text { curiosity }\end{array}$ & 1.533 & 2 & 0.465 \\
\hline C2. Inspire me & 1.451 & 2 & 0.484 \\
\hline C3. Interest me & 6.228 & 2 & 0.044 \\
\hline \multicolumn{4}{|l|}{ Affective } \\
\hline $\begin{array}{l}\text { A1. In a good } \\
\text { mood }\end{array}$ & 1.275 & 2 & 0.529 \\
\hline A2. Contented & 0.654 & 2 & 0.721 \\
\hline A3. Surprised & 0.253 & 2 & 0.881 \\
\hline \multicolumn{4}{|l|}{ Physical } \\
\hline P1. Comfort & 2.653 & 2 & 0.265 \\
\hline P2. Energy & 1.910 & 2 & 0.385 \\
\hline P3. Well-being & 2.603 & 2 & 0.272 \\
\hline $\begin{array}{l}\text { Overall } \\
\text { satisfaction }\end{array}$ & 3.574 & 2 & 0.167 \\
\hline $\begin{array}{l}\text { Intention to } \\
\text { repurchase }\end{array}$ & 4.750 & 2 & 0.093 \\
\hline
\end{tabular}

Table 3. Mann-Whitney-U tests and effect sizes

\begin{tabular}{l|l|l|l|l|l|l}
\hline $\begin{array}{l}\text { Cognitive Item } \\
\text { "Interest" }\end{array}$ & $\begin{array}{l}\text { Median } \\
\text { comparison }\end{array}$ & Mann-Whitney U & $\mathrm{Z}$ & $\begin{array}{l}\text { Exact. Sig. } \\
(2 \text {-tailed)* }\end{array}$ & $\left(\eta^{2}\right)$ & $\mathrm{d}_{\text {Cohen }}$ \\
\hline $\begin{array}{l}\text { Control } \\
\text { group-SST }\end{array}$ & $4-3$ & 143.5 & -2.435 & 0.0155 & 0.119 & 0.737 \\
\hline $\begin{array}{l}\text { Control } \\
\text { group-HG }\end{array}$ & $4-3$ & 113 & -1.443 & 0.151 & 0.049 & 0.452 \\
\hline SST-HG & $3-3$ & 87 & -0.314 & 0.767 & 0.003 & 0.116 \\
\hline
\end{tabular}

*Bonferroni corrected significance level $=0.016$

and the self-evaluation on "technology readiness" and "need for human interaction" in our small sample $(\mathrm{n}=28)$. Notably, it needs to be stated that the five participants who had no trust in data deletion, indicated maximum rating on the need for human interaction and lower indication for technology readiness. Finally, the evaluation shows that the two customers who were queued by the HG and exposed their name to the employee showed full trust in data deletion and the company, but would still not consider being notified by a text message sent to their private phones. The vast majority $(n=22)$ of customers 
queuing with technology $(\mathrm{n}=28)$ indicated a general preference towards interacting with the person who provides the service as an indicator for the construct "need for human touch" [42]. However, none of these results could be proven at a statistically significant level due to the small sample size.

\subsection{Qualitative Analysis of the Overall Customer Satisfaction}

In order to get a deeper insight into the evaluation of the overall experience, we used one item of customer satisfaction adapted from Turner and Shockley [29]. The answers have been coded by repetitive patterns given in the answers during the interviews. Table 4 provides the five most frequently mentioned answers and direct statements.

Table 4. Customer satisfaction statements

\begin{tabular}{|c|c|c|c|}
\hline$\#$ & Code & No. of times mentioned & $\begin{array}{l}\text { Example statement (translated } \\
\text { from German to English) }\end{array}$ \\
\hline 1 & Friendly employees & 28 & $\begin{array}{l}\text { "The service was perfect. The } \\
\text { employee was very friendly and } \\
\text { helpful" }\end{array}$ \\
\hline 2 & Competent employees & 23 & $\begin{array}{l}\text { "I have experienced very } \\
\text { courteous consultancy by the } \\
\text { service employee. She showed me } \\
\text { a lot of different options and how } \\
\text { to improve cost-effectiveness" } \\
\text { "The employee knows a lot about } \\
\text { Apple. I'm impressed" }\end{array}$ \\
\hline 3 & $\begin{array}{l}\text { Employees fulfilling } \\
\text { customer's needs }\end{array}$ & 17 & $\begin{array}{l}\text { "The employee was very } \\
\text { motivated to answer all of my } \\
\text { questions. Also, I had the feeling } \\
\text { to get a very individual } \\
\text { consultation. It was a very } \\
\text { positive experience" }\end{array}$ \\
\hline 4 & Satisfied feeling & 16 & $\begin{array}{l}\text { "I always leave this shop } \\
\text { satisfied" } \\
\text { "I'm very satisfied with the } \\
\text { performance in this store. } \\
\text { Actually, I came here today, to } \\
\text { terminate my contract. But now I } \\
\text { got a really good offer, which I } \\
\text { took" }\end{array}$ \\
\hline 5 & Helpful employees & 15 & $\begin{array}{l}\text { "My visit today was very } \\
\text { informative. Everything was done } \\
\text { satisfactorily. I only had a little } \\
\text { problem, but they helped me with } \\
\text { it" }\end{array}$ \\
\hline
\end{tabular}




\section{Discussion and Future Research}

In this study, we investigated the influence of human- and technology-based queuing technology on customers' evaluation of their experience and willingness to repurchase in a real-life retail setting. It is important for retailers to introduce some kind of queuing management in their stores where products or services require intensive consultation to be given by a service employee. For situations where several people request a service encounter at the same time, we strongly believe that having no queuing technology at all would result in an unfair and chaotic queuing situation, as Haynes [6] and Katz [4] claimed in their studies.

The intention of the retailer was to provide a relaxed and fair queueing process in the store. However, based on the observations we made when customers approached the store in the first section of our analysis, we point out that there are several issues to consider. We have noticed that customers are obviously used to screens that display the order of numbers in the queue and how many people are ahead of themselves. When this information was not provided, we got the impression that customers experienced stress observing the fair handling of the queue. Moreover, it is highly likely that customers would like to base their initial decision as to whether to join the queue or pass the store this time, on the total number of people in the queue. Furthermore, retailers must assume the fact that not all customers are aware of the purpose and function of the SST. Therefore, the purpose for which the SST exists should be clearly visible and easily understandable as should the information concerning how it can be used. In addition, we believe that the system would profit from a short demonstration video playing on the SST screen to show how the queuing process works and why name and number can be volunteered. Moreover, we believe that a service employee assisting customers to queue at the SST would help to better deal with the process.

Considering the statistical results from the adapted ISCX-measurement [15], we come to the conclusion that there are no pertinent differences concerning the cognitive, affective, and physical customer experience perception among customers using the queuing technology (SST, HG) or no technology at all. The item Interest, related to the cognitive construct, showed a significant difference between the SST and the HG in favour of the HG. However, we suggest not interpreting this single significant item as a strong result. Additionally, we measured no statistically significant difference in customers' overall satisfaction and intention to repurchase. Therefore, our study was not able to prove that the implementation of the queuing technologies (SST, HG) presented in this paper has a direct impact on the evaluation of the overall customer experience, measured by cognitive, affective and physical constructs. However, from a financial perspective, the SSTs might help retailers to save labour costs as these systems are able to take over human tasks during the queuing process [11] while the HG would require an additional employee to greet and queue customers. Moreover, we believe that in stores, where the customer frequency, and therefore waiting times, are generally higher, the presented advanced functions of the queuing technology (e.g. leaving the store to carry out errands) can be very helpful to reduce the unpleasant feeling of wasting time in the queue of a retail store. We argue that retailers with consultancy-intensive products should introduce some kind of queuing technology to provide an easy and fair management of customers. 
As assessed in the third part of our analysis, the evaluation of satisfaction for both queuing systems (SST and HG) demonstrates that customers were pleased with the necessary effort, ease, and speed. The three different notification options (i.e., ticket number, name, and text message by entering one's phone number) revealed that the willingness to expose one's name is much higher than the willingness to give the personal phone number. The fact that most of the participants who entered their name are male (10) would support Weijters et al.'s [34] TAM-based results which show that the influence of perceived usefulness on attitude towards using the SST is stronger for men than for women. Literature in brain research [45] has proven that the intention of calling customers by their names helps to personalize the experience as researchers detected greater brain activation when hearing one's own name. We assume that the decision to not expose the phone number during the queuing process is based on the lack of necessity at this stage. The impression that the phone number would be at everyone's disposal at the SST might evoke the feeling of discomfort and is likely to create involvement costs, which are too high for too little expected value. Another reason probably lies in the customer's general reluctance towards the exposure of personal data arising from repeated stories of data breaches recently reported in the media [46]. We strongly relate these results to the so-called "privacy paradox" which describes the contradiction between the customer's concerns about lack of privacy and carefree behaviour at the same time [47].

Finally, the answers to the qualitative question on the customer's whole experience of the store visit proved that the service provided by employees makes up the most important element of the whole experience. The queuing procedure and also the retail environment play a significant role in the impression of the brand and the store, but still, service capabilities remain in the mind of the customers after leaving the retailer's store rather than the whole experience. In contrast, we strongly believe that the queuing technology and its advanced features in stores, which have generally high customer frequency and consequently higher waiting times, can provide a major advantage for customers.

Some limitations of the study need to be mentioned as follows: First, we are aware that the small sample size distorted the results of the statistical analysis of customer experience, especially in terms of identifying differences between technology users $\left(\mathrm{n}_{\mathrm{HG}}=\right.$ 11. $\mathrm{n}_{\mathrm{SST}}=17$ ). Bigger samples, by surveying the same store for a longer period of time or by replicating the study in a more frequented store, would increase the statistical significance and decrease limitations in terms of the study's generalizability. Second, the factors influencing the participant's evaluation in field studies in a retail environment are countless. Future research may be applied in a laboratory environment to reduce the number of influencing factors. Third, the evaluation of the queuing process might be better scheduled directly after the actual transaction whereby researchers can be sure that the given answers are independent of the quality of products or the service encounter. Finally, future studies could investigate the experience of queuing technology in conjunction with cultural differences in the perception of waiting time, for example by adding Hofstede's [48] dimensions of culture. The implications of these points indicate further possibilities for future research in the domain of in-store technologies and customer experience. 


\section{Conclusion}

Our work contributes to the understanding of the impact of in-store retail technology on customer experience and intention to repurchase as demonstrated by the usage of SST and human-operated queuing technology in a retail environment. Even though we were not able to confirm strong evidence for differences between using queuing technology and directly approaching a service employee on customer experience factors in our adapted model, our findings show insights for retailers and practitioners related to introducing queuing management systems into their store as well as for developers designing such systems. In all cases, the focus of consultancy-intensive retail shops, such as telecommunication stores, lies on the capabilities of the service personnel. Queuing is one part of the whole experience, which could add good impressions and create the foundation for a good start into an individual's service encounter. Moreover, the absence of a convenient and fair queue management could cause anger and dissatisfaction for store visitors. However, customer satisfaction after the store visit depends on the degree of expectation fulfilment, the competence and friendliness of employees, and on whether customers are persuaded that they made a good deal or their problem has been solved. Therefore, in situations involving a short waiting time, as in our field study, we recommend introducing a FIFO queuing management system, which offers a convenient and fair experience for waiting customers. For highly frequented stores or especially busy phases, we strongly encourage retailers to introduce queuing technologies. We also believe that additional services, such as notifying the customer via text message, provide a great benefit for big stores, where customers expect longer waiting times. Additionally, we would recommend installing monitors that show the number of tickets ahead to provide visible evidence for the fairness of the queuing system. Being aware of important factors influencing the evaluation of queuing technology helps retailers and developers to understand the process and set the right management actions in terms of personnel planning and developing system features accordingly.

Acknowledgements. The present work was conducted within the Innovative Training Network project PERFORM funded by the European Union's Horizon 2020 research and innovation program under the Marie Skłodowska-Curie grant agreement No. 765395. This study reflects only the authors' view, the EU Research Executive Agency is not responsible for any use that may be made of the information it contains.

\section{References}

1. Voorhees, C.M., Baker, J., Bourdeau, B.L., Brocato, E.D., Cronin Jr., J.J.: It depends: moderating the relationships among perceived waiting time, anger, and regret. J. Serv. Res. 12, 138-155 (2009)

2. KPMG: Anteil der Befragten, die aus folgenden Gründe lieber in Online-Shops anstatt in Ladengeschäften einkaufen, weltweit im Jahr 2016 [Chart]. https://de.statista.com/statistik/ daten/studie/786111/umfrage/gruende-fuer-das-online-shopping-weltweit/

3. Larson, R.C.: OR forum-perspectives on queues: social justice and the psychology of queueing. Oper. Res. 35, 895-905 (1987) 
4. Katz, K., Larson, B., Larson, R.: Prescription for the waiting-in-line blues: entertain, enlighten, and engage. Sloan Manag. Rev. 4, 44-53 (1991)

5. Maister, D.H.: The Psychology of Waiting Lines. Harvard Business School, Boston (1984)

6. Haynes, P.J.: Hating to wait: managing the final service encounter. J. Serv. Mark. 4, 20-26 (1990)

7. Sasser, W.E., Olsen, R.P., Wyckoff, D.D.: Management of Service Operations: Text, Cases, and Readings. Allyn \& Bacon, Boston (1978)

8. Xu, S.H., Gao, L., Ou, J.: Service performance analysis and improvement for a ticket queue with balking customers. Manag. Sci. 53, 971-990 (2007)

9. Kuzu, K.: Comparisons of perceptions and behavior in ticket queues and physical queues. Serv. Sci. 7, 294-314 (2015)

10. Djelassi, S., Diallo, M.F., Zielke, S.: How self-service technology experience evaluation affects waiting time and customer satisfaction? A moderated mediation model. Decis. Support Syst. 111, 38-47 (2018)

11. Dabholkar, P.A.: Consumer evaluations of new technology-based self-service options: an investigation of alternative models of service quality. Int. J. Res. Mark. 13, 29-51 (1996)

12. Bitner, M.J.: Servicescapes: the impact of physical surroundings on customers and employees. J. Mark. 56, 57-71 (1992)

13. Kallweit, K., Spreer, P., Toporowski, W.: Why do customers use self-service information technologies in retail? The mediating effect of perceived service quality. J. Retail. Consum. Serv. 21, 268-276 (2014)

14. Colwell, S.R., Aung, M., Kanetkar, V., Holden, A.L.: Toward a measure of service convenience: multiple-item scale development and empirical test. J. Serv. Mark. 22, 160-169 (2008)

15. Bustamante, J.C., Rubio, N.: Measuring customer experience in physical retail environments. J. Serv. Manag. 28, 884-913 (2017)

16. Nosek, R.A., Wilson, J.P.: Queuing theory and customer satisfaction: a review of terminology, trends, and applications to pharmacy practice. Hosp. Pharm. 36(3), 275-279 (2001)

17. Klaus, P., Maklan, S.: EXQ: a multiple-item scale for assessing service experience. J. Serv. Manag. 23, 5-33 (2012)

18. Meyer, C., Schwager, A.: Understanding customer experience. Harvard Bus. Rev. 85, 116 (2007)

19. Lemon, K.N., Verhoef, P.C.: Understanding customer experience throughout the customer journey. J. Mark. 80, 69-96 (2016)

20. Schmitt, B.: Experiential marketing. J. Mark. Manag. 15, 53-67 (1999)

21. Lucia-Palacios, L., Pérez-López, R., Polo-Redondo, Y.: Cognitive, affective and behavioural responses in mall experience: a qualitative approach. Int. J. Retail Distrib. Manag. 44, 4-21 (2016)

22. Dahm, M., Wentzel, D., Herzog, W., Wiecek, A.: Breathing down your neck!: The impact of queues on customers using a retail service. J. Retail. 94, 217-230 (2018)

23. Babin, B.J., Darden, W.R., Griffin, M.: Work and/or fun: measuring hedonic and utilitarian shopping value. J. Consum. Res. 20, 644-656 (1994)

24. David, D., Miclea, M., Opre, A.: The information-processing approach to the human mind: basics and beyond. J. Clin. Psychol. 60, 353-368 (2004)

25. Poncin, I., Mimoun, M.S.B.: The impact of "e-atmospherics" on physical stores. J. Retail. Consum. Serv. 21, 851-859 (2014)

26. De Keyser, A., Köcher, S., Alkire, L., Verbeeck, C., Kandampully, J.: Frontline Service Technology infusion: conceptual archetypes and future research directions. J. Serv. Manag. 30, 156-183 (2019) 
27. Puccinelli, N.M., Goodstein, R.C., Grewal, D., Price, R., Raghubir, P., Stewart, D.: Customer experience management in retailing: understanding the buying process. J. Retail. 85, 15-30 (2009)

28. Verhoef, P.C., Lemon, K.N., Parasuraman, A., Roggeveen, A., Tsiros, M., Schlesinger, L.A.: Customer experience creation: determinants, dynamics and management strategies. J. Retail. 85, 31-41 (2009)

29. Turner, T., Shockley, J.: Creating shopper value: co-creation roles, in-store self-service technology use, and value differentiation. J. Promot. Manag. 20, 311-327 (2014)

30. Brakus, J.J., Schmitt, B.H., Zarantonello, L.: Brand experience: what is it? How is it measured? Does it affect loyalty? J. Mark. 73, 52-68 (2009)

31. Alexander, M., MacLaren, A., O'Gorman, K., White, C.: Priority queues: where social justice and equity collide. Tour. Manag. 33, 875-884 (2012)

32. Roy, S.K., Shekhar, V., Lassar, W.M., Chen, T.: Customer engagement behaviors: the role of service convenience, fairness and quality. J. Retail. Consum. Serv. 44, 293-304 (2018)

33. Obermeier, G., Auinger, A.: Human-computer interaction in physical retail environments and the impact on customer experience: systematic literature review and research agenda. In: Nah, F.F.-H., Siau, K. (eds.) HCII 2019. LNCS, vol. 11588, pp. 51-66. Springer, Cham (2019). https://doi.org/10.1007/978-3-030-22335-9_4

34. Weijters, B., Rangarajan, D., Falk, T., Schillewaert, N.: Determinants and outcomes of customers' use of self-service technology in a retail setting. J. Serv. Res. 10, 3-21 (2007)

35. Kembe, M.M., Onah, E.S., Iorkegh, S.: A study of waiting and service costs of a multi-server queuing model in a specialist hospital. Int. J. Sci. Technol. Res. 1, 19-23 (2012)

36. Psarros, I., Kepaptsoglou, K., Karlaftis, M.G.: An empirical investigation of passenger wait time perceptions using hazard-based duration models. J. Public Transp. 14, 6 (2011)

37. Bielen, F., Demoulin, N.: Waiting time influence on the satisfaction-loyalty relationship in services. Manag. Serv. Qual. 17, 174-193 (2007)

38. Google Developers: Responsive Web Design. https://developers.google.com/search/mobilesites/mobile-seo/responsive-design?hl=en

39. Questback GmbH: EFS Survey (2018)

40. Morgan, R.M., Hunt, S.D.: The commitment-trust theory of relationship marketing. J. Mark. 58, 20-38 (1994)

41. Parasuraman, A., Colby, C.L.: An updated and streamlined technology readiness index: TRI 2.0. J. Serv. Res. 18, 59-74 (2015)

42. Lee, H.-J., Yang, K.: Interpersonal service quality, self-service technology (SST) service quality, and retail patronage. J. Retail. Consum. Serv. 20, 51-57 (2013)

43. Corp, I.B.M.: Released. IBM SPSS Statistics for Windows, Armonk (2017)

44. Cohen, J.: Statistical Power Analysis for the Behavioral Sciences. Routledge, Abingdon (2013)

45. Carmody, D.P., Lewis, M.: Brain activation when hearing one's own and others' names. Brain Res. 1116, 153-158 (2006)

46. Chakraborty, R., Lee, J., Bagchi-Sen, S., Upadhyaya, S., Rao, H.R.: Online shopping intention in the context of data breach in online retail stores: an examination of older and younger adults. Decis. Support Syst. 83, 47-56 (2016)

47. Norberg, P.A., Horne, D.R., Horne, D.A.: The privacy paradox: personal information disclosure intentions versus behaviors. J. Consum. Affairs 41, 100-126 (2007)

48. Hofstede, G., Bond, M.H.: Hofstede's culture dimensions: an independent validation using Rokeach's value survey. J. Cross Cult. Psychol. 15, 417-433 (1984) 
Open Access This chapter is licensed under the terms of the Creative Commons Attribution 4.0 International License (http://creativecommons.org/licenses/by/4.0/), which permits use, sharing, adaptation, distribution and reproduction in any medium or format, as long as you give appropriate credit to the original author(s) and the source, provide a link to the Creative Commons license and indicate if changes were made.

The images or other third party material in this chapter are included in the chapter's Creative Commons license, unless indicated otherwise in a credit line to the material. If material is not included in the chapter's Creative Commons license and your intended use is not permitted by statutory regulation or exceeds the permitted use, you will need to obtain permission directly from the copyright holder.

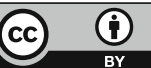

